\title{
Novel locked nucleic acid (LNA)-based probe for the rapid identification of Chlamydia suis using real-time PCR
}

\author{
Paweł Lis ${ }^{1}$, Aleksandra Kumala ${ }^{1}$, Mirosław Spalinski ${ }^{2}$ and Krzysztof Rypula ${ }^{1 *}$
}

\begin{abstract}
Background: As the importance of chlamydial infections in pigs has become more obvious, a rapid and sensitive method to study the prevalence of Chlamydia suis in pig herds is required. Such a method should permit routine diagnostic tests for herds with clinical and subclinical infections, without the need for Chlamydia culture.

Results: The main objective of this study was to develop a specific and rapid method for detecting C. suis in swine herds. A real-time PCR assay using a single locked nucleic acid (LNA)-containing probe specific for $C$. suis was developed based on the previously described 28S rDNA fragment used to identify Chlamydiales. Use of LNA nucleotides enabled the single probe to target a short, specific fragment of the $23 \mathrm{~S} r \mathrm{RNA}$. The probe showed high specificity for $\mathrm{C}$. suis and did not show any cross-reactivity with other Chlamydia or Chlamydophila species nor with swine DNA. All of the 86 tested field isolates, earlier identified as C. suis, were confirmed as positive using the newly developed assay.

Conclusions: Using single LNA-based C. suis-specific probe allowed rapid and simple identification of this pathogen without requiring sequencing analysis and culturing. The proposed method may be used to study the prevalence of $C$. suis infection in pig herds and as a routine diagnostic test for herds with clinical and subclinical infection.
\end{abstract}

Keywords: Chlamydia suis, Pigs, Diagnostics, Real-time PCR, Probe, LNA

\section{Background}

Chlamydia suis, Chlamydophila abortus, Chlamydophila psittaci and Chlamydophila pecorum infections have been identified in pigs. Recent studies indicate that these infections occur more frequently than originally thought [1-4]. In particular, the study 'Animal Chlamydiosis and its zoonotic implications' by Action 855 of the European Cooperation in Science and Technology brought the economic importance of chlamydial infections in pigs into sharp focus. Chlamydial infections have been implicated in a wide spectrum of clinical disorders, including reproductive disorders, ocular and respiratory problems (e.g. conjunctivitis and pneumonia), enteritis, pleuritis, and polyarthritis [4]. Chlamydia can cause both acute

\footnotetext{
*Correspondence: krzysztof.rypula@up.wroc.pl

'Division of Infectious Diseases and Veterinary Administration, Department of Epizootiology with Clinic of Birds and Exotic Animals, Faculty of Veterinary Medicine, University of Environmental and Life Sciences, Grunwaldzki Square 45, 50-366 Wrocław, Poland

Full list of author information is available at the end of the article
}

and latent disease forms, and very often, chlamydial diseases are asymptomatic.

C. suis appears to be both common and widespread, often occurring in mixed infections with $C p$. abortus, $C p$. psittaci, and Cp. pecorum [5]. The pig intestine is considered to be the natural reservoir for C. suis [6]. The latent presence of chlamydia in the alimentary tract can result in systemic infection when the bacteria reach the epithelial and cellular layers. When the lymph system is affected, the process is called chlamydiosis [7]. C. suis has been identified with high prevalence in growing pigs with or without diarrhoea, as well as in finisher pigs with or without conjunctivitis [4]. A correlation has been noted between samples with a high degree of infection and the presence of clinical signs of chlamydial disease. The use of intensive pig production systems might increase the risk of chlamydial disease in pigs [6].

In gnotobiotic pig challenge studies, $C$. suis caused diarrhoea in young piglets, and chlamydial antigens were identified in these animals. Chlamydia was also found in enterocytes isolated from the intestinal tissue and faeces 
$[7,8]$. Experimental aerosol challenge of 7-day-old pigs with $C$. suis confirmed the pathogenic potential of $C$. suis in the porcine respiratory system. All infected animals showed clinical signs, including dry cough, serous nasal discharge, and severe dyspnoea with wheezing, shortness of breath, and breathlessness. The body temperatures of the infected animals rose above $40^{\circ} \mathrm{C}[9,10]$. Another study conducted in Germany and Switzerland demonstrated a high prevalence of $C$. suis in the eyes of pigs with ocular symptoms [11]. C. suis has been investigated in pigs in association with reproductive disorders, such as return to oestrus (with early embryonic death in $>50 \%$ of sows) and inferior semen quality (with decreased sperm cell motility and death of $>50 \%$ of sperm cells). These pathologies have been demonstrated on farms in Belgium, Cyprus, Estonia, Germany, Israel, and Switzerland [1,12-14]. C. suis alone may be responsible for diarrhoea in young piglets, resulting in the partial loss of litters and increased owner costs incurred on veterinary care. However, the clinical importance of these disorders appears to decrease in concert with the growth of the animals [8]. Necropsy and pathological investigations may be a first step in the analysis of the source of losses. In a study of field infections, however, pathogen (C. suis)-related lesions appeared in 50\% of the samples examined [4].

Using a locked nucleic acid (LNA)-containing probe, in this study, we evaluated a real-time PCR assay specific for $C$. suis. This assay is based on the previously described $28 \mathrm{~S}$ rDNA that was used for the identification of Chlamydiales [15]. The LNA nucleotides, which have an additional methylene bridge between the 2 ' oxygen and the $4 '$ carbon of the ribose ring, exhibit much higher binding affinity than unmodified nucleotides. Compared to standard DNA probes, the locked structure results in higher sensitivity and increased specificity of the LNAcontaining probes [16]. These characteristics enable the use of much shorter probes (7-10 nucleotides) and simplify the identification of appropriate regions for probe hybridization.

\section{Methods}

\section{Sample collection}

This study included 86 field archival isolates of C. suis from years 2011-2013, which were derived from clinically healthy animals and pigs with clinical disorders (i.e. conjunctivitis cases and reproductive disorders in sows). The research was conducted in closed-loop farms with 20-120 adult sows in each basic herd. Ten farms were tested. The required sample size was computed in WinEpiscope 2.0 (EPIDECON), assuming an expected prevalence of $30 \%$ and a confidence level of $95 \%$.

Conjunctival swabs from both eyes and a swab from the vaginal vestibule were collected from each sow. The specimens were stabilized by using the PAXgene Tissue
Stabilizer (Qiagen, Poland) and stored at $-80^{\circ} \mathrm{C}$. Reference strains of positive DNA for other chlamydial organisms were as follows: C. suis VR-1474 (ATCC, USA), Chlamydia trachomatis and Chlamydophila abortus (NRVI, Puławy, Poland), Chlamydophila felis strain 905 (Merial, France), and Chlamydophila psittaci (field isolate obtained from birds, shared by Dr. T. Piasecki, Wroclaw University of Environmental and Life Sciences, Poland). Mycoplasma spp. ATCC 2391 (LGC Standards, Poland) and S. epidermidis ATCC 35984 (PAN, Wroclaw, Poland) were included as controls.

DNA was extracted and purified with a GeneJET Viral DNA and RNA Purification Kit, according to the manufacturer's manual (Thermo Scientific, Lithuania). All DNA samples were tested by using the qPCR procedure described by Everett et al. [15] and sequencing the obtained products.

\section{Design of the assay}

Primers and probe were designed by using the chlamydial sequences available in GenBank and were evaluated with Primer3 [17]. Table 1 shows the list of sequences of the 23S rRNA gene and the genome sequences from GenBank used in the development of the primers and probes. Sequences were aligned and analysed using MEGA6 software [18]. Figure 1 shows the sequence recognized by the C. suis-specific LNA probe and the homologous sequences from the closely related $C$. trachomatis and $C p$. abortus genomes.

Products obtained with real-time PCR were sequenced (Genomed, Poland) and identified using BLAST (blast. ncbi.nlm.nih.gov). Oligonucleotides were synthesized by Sigma-Aldrich. Primer and probe sequences used for

\begin{tabular}{|c|c|c|}
\hline Species & Strain & NCBI accession number \\
\hline Chlamydia muridarum & Nigg CM972 & СР006975.1 \\
\hline \multirow[t]{5}{*}{ Chlamydia suis } & R19 & AF481047.1 \\
\hline & R24 & U68428.1 \\
\hline & R27 & U68429.1 \\
\hline & MSO4 & DQ118376.1 \\
\hline & $\mathrm{H} 5$ & U68427.1 \\
\hline Chlamydia trachomatis & C/TW-3 & СР006945.1 \\
\hline Chlamydophila abortus & $S 26 / 3$ & CR848038.1 \\
\hline Chlamydophila caviae & GPIC & AE015925.1 \\
\hline Chlamydophila felis & $\mathrm{Fe} / \mathrm{C}-56$ & NR_076260.1 \\
\hline Chlamydophila pecorum & P787 & СР004035.1 \\
\hline Chlamydophila pneumoniae & CWL029 & NR_076161.1 \\
\hline Chlamydophila psittaci & WS/RT/E30 & СР003794.1 \\
\hline
\end{tabular}




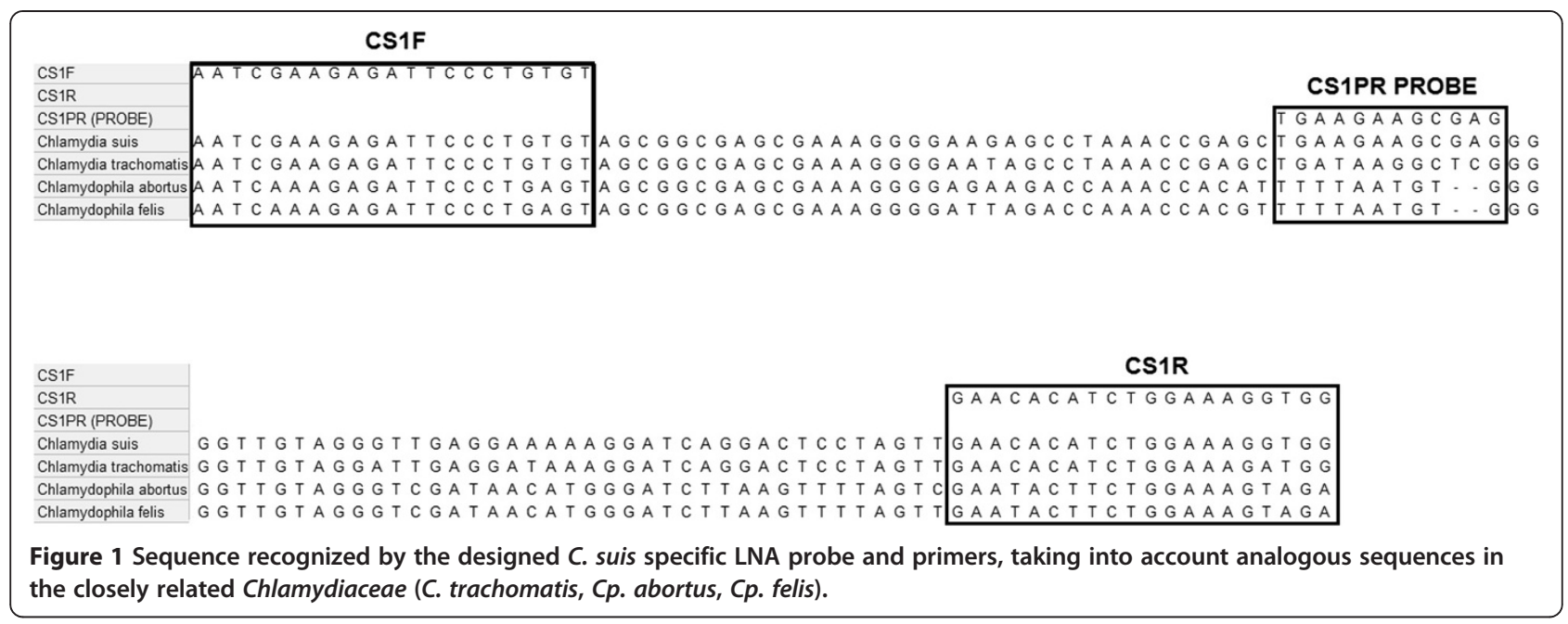

verification of the diagnostic method are provided in Table 2.

To validate each new set of primers, a classic PCR was performed, followed by qPCR with SYBR Green. Next, the qPCR was tested with the designed LNA probe. The primer sets proposed in this study were specific for the 23S rRNA gene. Each sample was tested in triplicate. Serial 10-fold dilutions were performed on the C. suispositive sample to assess the test sensitivity. The spectrophotometrically determined mean DNA concentration of the reference strain was $6 \mathrm{ng} / \mu \mathrm{l}$.

\section{PCR procedures}

The classic PCR was performed using $2.5 \mu$ l of DreamTaq Green buffer, $0.5 \mu \mathrm{l}$ of dNTPs $(10 \mathrm{mM}), 1 \mu \mathrm{l}$ of CS1F $(10 \mu \mathrm{M}), 1 \mu \mathrm{l}$ of CS1R $(10 \mu \mathrm{M}), 0.2 \mu \mathrm{l}$ of DreamTaq DNA polymerase (Thermo Scientific), and $18.8 \mu \mathrm{l}$ of water. Each reaction included $1 \mu \mathrm{l}$ of matrix DNA. The cycling conditions were $3: 00$ at $95^{\circ} \mathrm{C} ; 40$ cycles of $95^{\circ} \mathrm{C}$ for $0: 30,48^{\circ} \mathrm{C}$ for 0:30, $72^{\circ} \mathrm{C}$ for 0:30; and 5:00 at $72^{\circ} \mathrm{C}$.

Reaction mixtures for real-time PCR with the TQF/ TQR primers and probe, as described by Everett et al. [15], contained $10 \mu \mathrm{l}$ of KAPA PROBE FAST Bio-Rad iCycler $2 \times$ qPCR Master Mix (KapaBiosystems, USA), $0.3 \mu \mathrm{l}$ of each primer $(10 \mu \mathrm{M}), 0.2 \mu \mathrm{l}$ of the probe $(10 \mu \mathrm{M}), 4.2 \mu \mathrm{l}$ of miliQ water, and $5 \mu \mathrm{l}$ of genomic
DNA. The real-time PCR cycling included 40 cycles of $0: 15$ at $95^{\circ} \mathrm{C}$ and $1: 00$ at $60.5^{\circ} \mathrm{C}$, with an initial denaturation for 3:00 at $94^{\circ} \mathrm{C}$. Real-time PCR was performed in a Bio-Rad iQ5 (Bio-Rad, Poland). The following reaction mixture was used for the real-time PCR with the CS1PR probe: $10 \mu \mathrm{l}$ of KAPA PROBE FAST Bio-Rad iCycler $2 \times$ qPCR Master Mix, $0.4 \mu \mathrm{l}$ of each primer $(10 \mu \mathrm{M}), 0.4 \mu \mathrm{l}$ of probe $(10 \mu \mathrm{M}), 7.8 \mu \mathrm{l}$ of miliQ water, and $1 \mu \mathrm{l}$ of gDNA. The cycling conditions were 40 cycles of 0:03 at $95^{\circ} \mathrm{C}$ and $0: 20$ at $48^{\circ} \mathrm{C}$, with an initial denaturation of $3 \mathrm{~min}$ at $94^{\circ} \mathrm{C}$. Real-time PCR was performed using a Bio-Rad iQ5. The SYBR Green assay was performed using the same parameters and the KAPA SYBR ${ }^{\circ}$ FAST Bio-Rad iCycler 2× qPCR Master Mix.

\section{Ethic statement}

The Ethical Committee for Animal Experiments, Wrocław, Poland, approved this study and all owners provided informed consent prior to initiation.

\section{Results}

Traditional PCR reactions were conducted to test the specificity of the designed primers. The CS1F and CS1R primers amplified a 128-bp fragment of the $23 \mathrm{~S}$ rRNA gene, showing a positive signal in PCRs using C. suis, $C p$. abortus, C. trachomatis, and Cp. felis DNA. No products

Table 2 Sequences of primers and probes used during the study

\begin{tabular}{lll}
\hline & Sequence (5'-3') & Source \\
\hline CS1F & AATCGAAGATTCCCTGTGT & This study \\
CS1R & CCACCTTCCAGATGTGTC & This study \\
CS1PR & FAM- T [+G] A [+A] [+G] A [+A] GC [+G] [+A] G -BHQ1 & This study \\
TQF & GAAAGAACCCTTGTTAAGGGG & Everett et al. [15] \\
TQR & CTTAACTCCCTGGCTCATCATG & Everett et al. [15] \\
Probe & FAM-CAAAAGGCACGCCGTCAAC-TAMRA & Everett et al. [15] \\
\hline
\end{tabular}

$[+N]-$ LNA BASES. 
were observed in reactions containing $C p$. psittaci, $M$. felis, S. epidermidis, or swine DNA (Figure 2).

Subsequently, real-time PCR was performed using the CS1F and CS1R primers and C. suis gDNA. One clear peak was visible in the melting curve analysis, indicating that a single amplicon was obtained in the real-time PCR procedure (Figure 3).

The PCR product was sequenced, and the identified sequence was identical to the C. suis R19 23S rRNA gene fragment sequence obtained from GenBank (AF481047.1).

The CS1PR probe was designed to recognize C. suis specifically, while excluding other chlamydial sequences available in GenBank to avoid any cross-reactivity. Use of LNA nucleotides enabled us to develop a short (12 nt), yet specific, probe. Real-time PCR using the CS1PR probe showed no positive signals when DNA isolated from $C$. trachomatis, Cp. abortus, Cp. psittaci, Cp. felis, M. felis, S. epidermidis, or swine DNA was used as a template.

Six serial 10-fold dilutions of C. suis gDNA isolated from pure culture were used to determine the assay sensitivity. The range of detection of the assay was between a $C_{\mathrm{T}}$ of 13 (6 ng of genomic DNA) and a $C_{\mathrm{T}}$ of 36 (60 fg of genomic DNA), indicating that the lowest amount of genomic DNA detectable by the assay was $60 \mathrm{fg}$ (about 50 copies; Figure 4). Correlation coefficients of the standard curves were all above 0.96 , and the efficiency of the reaction was $98.9 \%$ (slope: $-3.349 \pm 0.3727$ ). All 86 of the field isolates selected with the Chlamydiaceae-specific probe and identified as $C$. suis by sequencing of the PCR product as in Everett et al. [15] were confirmed as positive by the CS1PR probe.

\section{Discussion}

The rate of Chlamydiaceae seroprevalence in pig farms across European countries, including Germany, Belgium, and Switzerland, differs greatly. Frequently, seroprevalence depends on the age of pigs examined, although seropositivity has been confirmed in all phases of pig production. The lowest rate $(6.9 \%)$ was observed in piglets younger than 4 weeks old, whereas the rate reached $48.1 \%$ in older pigs [1]. In sows specifically, the reported seroprevalence ranges from 33\% to $72 \%$ [12]. In Belgian fattening farms, sow seropositivity has been reported to be as high as $96.5 \%$ [2]. A previous study reported seropositivity to C. suis in pigs from all 11 farms investigated, with seropositivity rates ranging from $20 \%$ to $100 \%$ [19].

Guscetti et al. [20] investigated C. suis infection in gnotobiotic piglets. Animals were inoculated with egggrown chlamydiae at 2-3 days of age and were observed for clinical signs. Animals were sacrificed and necropsied at 2-13 days post-inoculation, and serological tests were performed (complement fixation test and ELISA). Clinical symptoms, including diarrhoea, slight and transient anorexia, weakness, and body weight loss, were observed. Immunohistochemistry and ELISA revealed that chlamydial replication was particularly marked at $2-4$ post-inoculation and primarily located in the small intestine. However, all sera were negative for antichlamydial antibodies [20]. In general, intensively kept pigs are predisposed to ocular chlamydial infection associated with conjunctivitis [11].

Cell culture is widely regarded as the gold standard in chlamydial diagnosis. However, this method has numerous limitations, particularly in the case of $C$. suis, which displays limited growth in commercial cell lines [21]. In commercial laboratories, the species-specific identification of pathogens is uncommon because specimens collected in the field are generally diagnosed only to the Chlamydiaceae family level. Consequently, the epidemiological situation remains largely unknown, as individual pathogens are not considered. As a diagnostic approach, PCR detection of $C$. suis provides more satisfactory results than direct culture, particularly if percent positivity is considered ( $42 \%$ vs. $33 \%$ ) [22]. The sensitivity and specificity of the reaction proposed by Sachse et al. were $94.4 \%$ and $81.0 \%$, respectively [22].

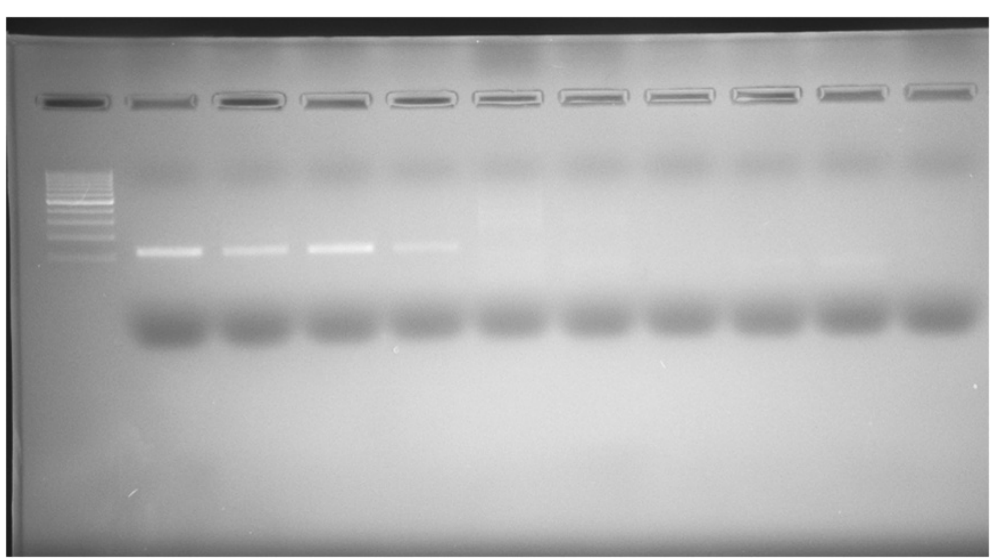

Figure 2 Results of the amplification of the fragment of $23 \mathrm{~S}$ rRNA gene using CS1F/CS1R primers. On the gel, from the left: $100 \mathrm{bp}$ ladder; C. suis; Cp. abortus; C. trachomatis; Cp. felis; Cp. psittaci; M. felis; S.epidermidis; swine DNA; NTC. 


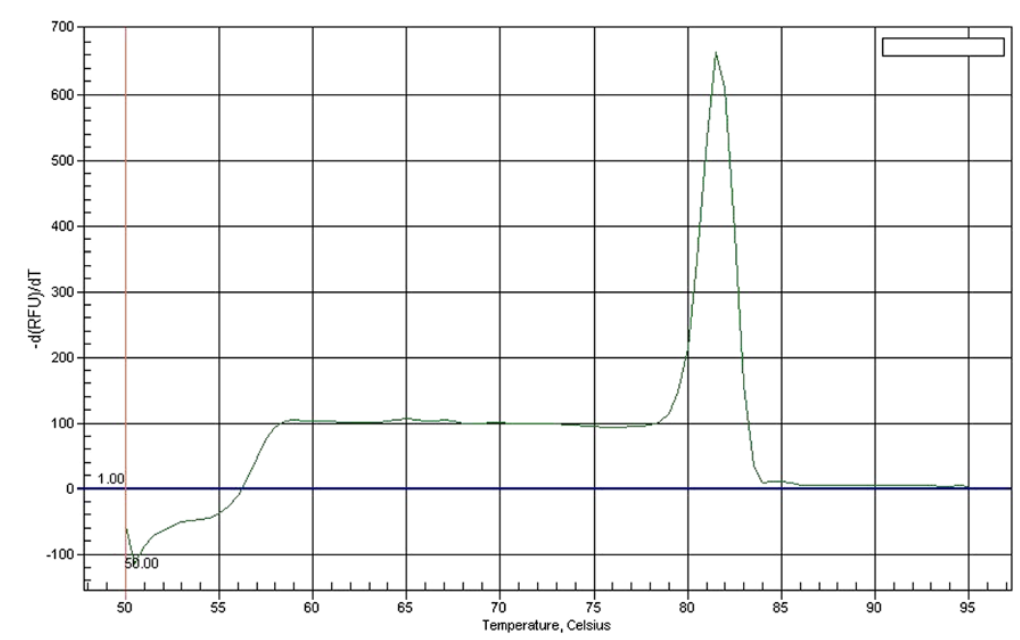

Figure 3 Melting curve of the product of the amplification of the C. suis $23 S$ rRNA gene fragment using CS1F/CS1R primers.

The very high sensitivity of real-time PCR enables direct identification from swabs without prior propagation of the pathogen by cell culture. Current PCR tests proposed by various researchers for the identification of Chlamydiaceae in pigs target the ompA, 16S-23S rRNA, or incA gene. Species-specific real-time PCR tests proposed for pigs detect the ribosomal intergenic spacer and domain I of the $23 \mathrm{~S}$ rRNA gene [6]. Using the PCR-RFLP method described by Demkin and Zimin [23], we were unable to obtain product using material isolated from swabs, indicating that classical PCR is was not sensitive enough for identification of Chlamydiaceae from this type of material without culturing (unpublished data).

In this study, we designed a real-time PCR assay for the identification of $C$. suis. To our knowledge, this is the first report of a C. suis-specific real-time PCR method that allows the highly specific and sensitive detection and species-level identification of the pathogen with a single oligonucleotide LNA-based probe and without requiring sequencing analysis. Using LNA nucleotides allowed us to target a short, specific fragment of the 23S rRNA gene for development of the C. suis-specific probe. The proposed method may be used to study the prevalence of $C$. suis infection in pig herds and as a routine diagnostic test for herds with clinical and subclinical infection. Speciesspecific identification may be important therapeutically, because the only known stable tetracycline-resistant strains of Chlamydia are C. suis.

\section{Conclusions}

We designed a single LNA-based C. suis-specific probe that allowed rapid and simple identification of this pathogen using real-time PCR, without requiring sequencing analysis and culturing. 86 C. suis-positive samples were tested and successfully identified using the newly designed probe, showing high specificity and sensitivity of the described method. The proposed assay may be used to study the prevalence of $C$. suis infection and as a routine diagnostic test for herds with clinical and subclinical infection.

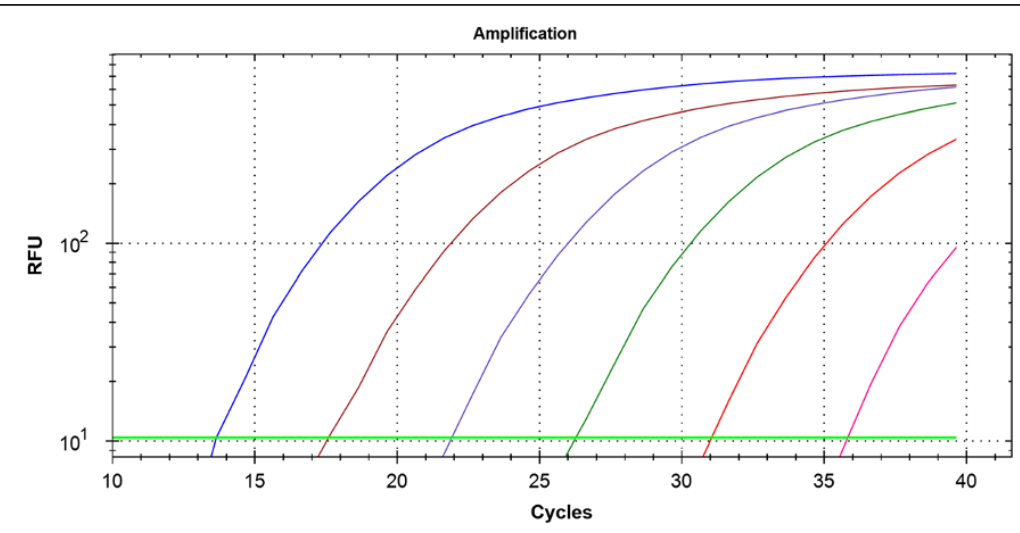

Figure 4 Real time-PCR assay with CS1PR probe performed on serial 10-fold dilutions of C. suis genomic DNA (6 ng to $60 \mathrm{fg}$ of DNA). 


\section{Competing interests}

The authors declare that they have no competing interests.

\section{Authors' contribution}

$\mathrm{PL}$ participated in the design of the assay, carried out the PCR studies and drafted the manuscript. AK participated in isolation and identification of the samples, helped in the PCR studies and helped to draft the manuscript. MS collected the samples and helped to draft the manuscript. KR conceived of the study, participated in its design and coordination and helped to draft the manuscript. All authors read and approved the final manuscript.

\section{Acknowledgements}

This study was supported by funds from the by grant NN 308578240 from the National Committee for Scientific Research Poland.

\section{Author details}

${ }^{1}$ Division of Infectious Diseases and Veterinary Administration, Department of Epizootiology with Clinic of Birds and Exotic Animals, Faculty of Veterinary Medicine, University of Environmental and Life Sciences, Grunwaldzki Square 45, 50-366 Wrocław, Poland. Veterinary Practice CHIRION, Błonie 3 17-120, Brańsk.

Received: 21 June 2014 Accepted: 18 September 2014

Published online: 24 September 2014

\section{References}

1. Camenisch U, Lu ZH, Vaughan L, Corboz L, Zimmermann DR, Wittenbrink MM, Pospischil A, Sydler T: Diagnostic investigation into the role of Chlamydiae in cases of increased rates of return to oestrus in pigs. Vet Rec 2004, 155:593-596.

2. Vanrompay D, Geens T, Desplanques A, Hoang TQ, De Vos L, Van Loock M, Huyck E, Mirry C, Cox E: Immunoblotting, ELISA and culture evidence for Chlamydiaceae in sows on 258 Belgian farms. Vet Microbio/ 2004, 99:59-66.

3. Kauffold J, Melzer F, Berndt A, Hoffmann G, Hotzel H, Sachse K: Chlamydiae in oviducts and uteri of repeat breeder pigs. Theriogenology 2006, 66:1816-1823.

4. Englund S, af Segerstad CH, Arnlund F, Westergren E, Jacobson M: The occurrence of Chlamydia spp. in pigs with and without clinical disease. BMC Vet Res 2012, 26:8-9.

5. Longbottom D: Chlamydial infections of domestic ruminants and swine: new nomenclature and new knowledge. Vet J 2004, 168:9-11.

6. Schautteet K, Vanrompay D: Chlamydiaceae infections in pig. Vet Res 2011, 42:1-10.

7. Bagdonas J, Mauricas M, Gerulis G, Masilionis M, Martinov S: Incidence of pig chlamydiosis in Lithuania revealed by different techniques. Biotechnol Biotechnol Eq 2004, 2:166-176.

8. Nietfeld JC, Janke BH, Leslie-Steen P, Robison DJ, Zeman DH: Small intestinal Chlamydia infection in piglets. J Vet Diagn Invest 1993, 5:114-117.

9. Rogers DG, Andersen AA, Hunsaker BD: Lung and nasal lesions caused by a swine chlamydial isolate in gnotobiotic pigs. J Vet Diagn Invest 1996, 8:45-55.

10. Reinhold P, Kirschvink N, Theegarten D, Berndt A: An experimentally induced Chlamydia suis infection in pigs results in severe lung function disorders and pulmonary inflammation. Vet Res 2008, 39:1-19.

11. Becker A, Lutz-Wohlgroth L, Brugnera E, Lu ZH, Zimmermann DR, Grimm F, Grosse BE, Kaps S, Spiess B, Pospischil A, Vaughan L: Intensively kept pigs pre-disposed to chlamydial associated conjunctivitis. J Vet Med A Physiol Pathol Clin Med 2007, 54:307-313.

12. Eggemann G, Wendt M, Hoelzle LE, Jager C, Weiss R, Failing K: Prevalence of chlamydial infections in breeding sows and their correlation to reproductive failure. Dtsch Tierarztl Wochenschr 2000, 107:3-10.

13. Schautteet K, Beeckman DS, Delava P, Vanrompay D: Possible pathogenic interplay between Chlamydia suis, Chlamydophila abortus and PCV-2 on a pig production farm. Vet Rec 2010, 166:329-333.

14. Hoelzle LE, Steinhausen G, Wittenbrink MM: PCR-based detection of chlamydial infection in swine and subsequent PCR-coupled genotyping of chlamydial omp1-gene amplicons by DNA-hybridization, RFLP- analysis, and nucleotide sequence analysis. Epidemiol Infect 2000, 125:427-439.

15. Everett KD, Hornung $\sqcup$, Andersen AA: Rapid detection of the Chlamydiaceae and other families in the order Chlamydiales: three PCR tests. J Clin Microb 1999, 37:575-580.
16. Priya NG, Pandey N, Rajagopal R: LNA probes substantially improve the detection of bacterial endosymbionts in whole mount of insects by fluorescent in-situ hybridization. BMC Microbio/ 2012, 24:12-18.

17. Untergrasser A, Cutcutache I, Koressaar T, Ye J, Faircloth BC, Remm M, Rozen SG: Primer3 - new capabilities and interfaces. Nucl Acid Res 2012, 40:115.

18. Tamura K, Stecher G, Peterson D, Filipski A, Kumar S: MEGA6: molecular evolutionary genetics analysis version 6.0. Mol Biol Evol 2013, 30:2725-2729.

19. Di Francesco A, Baldelli R, Cevenini R, Magnino S, Pignanelli S, Salvatore D, Galuppi R, Donati M: Seroprevalence to chlamydiae in pigs in Italy. Vet Rec 2006, 159:849-850.

20. Guscetti F, Schiller I, Sydler T, Heinen E, Pospischil A: Experimental enteric infection of gnotobiotic piglets with Chlamydia suis strain $\mathbf{S 4 5}$. Vet Microbiol 2009, 135:157-168.

21. Niemczuk K, Truszczyński M: Pathogenicity of the microorganisms of the family Chlamydiaceae respecting the changes in their classification. Pol J Vet Sci 2002, 5:99-101.

22. Sachse K, Grossmann E, Jäger C, Diller R, Hotzel H: Detection of Chlamydia suis from clinical specimens: copmarison of PCR, antigen ELISA, and culture. J Microbiol Meth 2003, 54:233-238.

23. Demkin W, Zimin AL: A new amplification target for PCR-RFLP detection and identification of Chlamydiaceae species. Arch Microbiol 2005, 183:169-175.

doi:10.1186/s12917-014-0225-4

Cite this article as: Lis et al:: Novel locked nucleic acid (LNA)-based probe for the rapid identification of Chlamydia suis using real-time PCR. BMC Veterinary Research 2014 10:225.

\section{Submit your next manuscript to BioMed Central and take full advantage of:}

- Convenient online submission

- Thorough peer review

- No space constraints or color figure charges

- Immediate publication on acceptance

- Inclusion in PubMed, CAS, Scopus and Google Scholar

- Research which is freely available for redistribution 